\title{
Common polymorphisms of calpain- 10 and the risk of Type 2 Diabetes in a Tunisian Arab population: a case-control study
}

\author{
Intissar Ezzidi1, Amira Turki1, Safia Messaoudi¹, Molka Chaieb³, Maha Kacem4, Ghada M Al-Khateeb5, \\ Touhami Mahjoub1, Wassim Y Almawi ${ }^{5}$ and Nabil Mtiraoui*1,2
}

\begin{abstract}
Background: Genetic variations in the calpain-10 gene (CAPN10), in particular the at-risk diplotype (112/121), were previously implicated with increased risk of type 2 diabetes (T2D).

Methods: We examined the association of CAPN10 UCSNP-43 (rs3792267), UCSNP-19 (rs3842570), and UCSNP-63 (rs5030952) SNPs with T2D in 917 Tunisian T2D patients and 748 non-diabetic controls. CAPN10 genotyping was done by PCR-RFLP.

Results: Enrichment of UCSNP-19 2R (minor) allele and 2R/2R genotype was found in T2D patients; the allele and genotype distribution of UCSNP-43 and UCSNP-63 alleles and genotypes were not significantly different between patient groups and non-diabetic control subjects. Regression analysis demonstrated progressive increases in T2D risk in $3 R / 2 R[O R(95 \% \mathrm{Cl})=1.35(1.08-1.68)]$ and $2 \mathrm{R} / 2 \mathrm{R}[\mathrm{OR}(95 \% \mathrm{Cl})=1.61(1.20-2.18)]$ genotypes. Of the six haplotypes detected, enrichment of haplotype 111 (UCSNP-43/UCSNP-19/UCSNP-63) was seen in patients ( $P C=0.034$ ); the distribution of the other haplotypes was comparable between patients and control subjects; neither haplotype 211 nor haplotype 212 was observed. Furthermore, the frequency of all CAPN10 diplotypes identified, including the "highrisk diplotype (112/121) reported for Mexican-Americans and Northern Europeans, were comparable between patients and controls.
\end{abstract}

Conclusions: CAPN10 UCSNP-19 variant, and the 111 haplotype contribute to the risk of T2D in Tunisian subjects; no significant associations between CAPN10 diplotypes and T2D were demonstrated for Tunisians.

\section{Background}

Type 2 diabetes (T2D) is a metabolic disorder characterized by impaired insulin-stimulated glucose uptake in muscle and fat, altered glucose-induced insulin secretion, and increased hepatic glucose production. Insofar as T2D is triggered by genetic and environmental risk factors, several genome-wide scan studies on different ethnic groups reported linkage at the same or different chromosomes with T2D [1,2]. Of the diabetes-related genes, fine mapping and positional cloning suggested that the calpain-10 (CAPN10) gene might serve as an important T2D susceptibility gene $[3,4]$. Similar to other calpains,

\footnotetext{
* Correspondence: mtiraouinabil@yahoo.fr

1 Research Unit of Biology and Genetics of Hematological and Auto-immune diseases, Faculty of Pharmacy of Monastir, University of Monastir, Tunisia Full list of author information is available at the end of the article
}

CAPN10 consists of an isoform-specific large subunit and a common small subunit, and was shown to function as intracellular calcium-dependent cysteine proteases in calcium-regulated signaling pathways [5]. CAPN10 is expressed at the mRNA and protein levels by several tissue types, with different mRNA isoforms reported, in particular those involved in the regulation of glucose homeostasis, such as pancreatic $\beta$ islet cells, liver, skeletal muscle, and adipocytes [6,7].

CAPN10 is located on chromosome 2q37.3, and comprises 15 exons spanning $31 \mathrm{~kb}$, and encodes a 672 amino-acid intracellular protease. Several case control and association studies indicated that polymorphisms in CAPN10 are associated with the development of T2D and insulin resistance, more so in obese patients with an earlier age of disease onset [6,8-10]. These include the at- 
risk UCSNP-43 G/A variant located in the third intron, UCSNP-19 2R (two 32-bp repeats)/3R (three 32-bp repeats) present in intron 6 , and UCSNP-63 C/T variant within CAPN10 intron $13[7,10]$. This contribution of the CAPN10 variants to T2D pathogenesis was highlighted by the findings that select UCSNP-43/UCSNP-19/ UCSNP -63 haplotypes (112 and 121) were associated with heightened risk of T2D in select ethnic groups, and as at-risk dipolotypes (haplotype combinations) were reported for many populations [10-13]. The reported association of UCSNP-43/UCSNP-19/UCSNP -63 112/ 121 diplotype with increased T2D risk in Mexicans Americans, German and Finnish populations exemplified this association $[10,11]$.

A number of studies from diverse populations have confirmed the initial findings $[6,14]$, while some did not $[15,16]$. Others showed a trend towards significance, but were underpowered to detect a meaningful effect [17]. We previously reported on the association of select variants of the recently identified T2DM candidate genes with T2D in Tunisia [18]. The aim of this study was to investigate whether UCSNP-43, UCSNP-19, and UCSNP63 CAPN10 variants, alone or at-risk haplotype and haplotype combination (diplotype] were associated with T2D in a group of Tunisian T2D patients and non-diabetic control subjects.

\section{Methods}

\section{Study population}

A total of 917 consecutive unrelated adult patients with documented medical records of T2D were recruited from outpatient endocrinology clinics in Southern, Central and Northern Tunisia by referral from the treating physician, after obtaining initial verbal consent to participate in the study. In addition, 748 control subjects from the same area as the patients, and comprising blood donors, healthy volunteers, or hospital/university staff members were enrolled in this study. Controls were frequencymatched with patients according to age $(P=0.160)$, ethnic origin (all of Arab descent), and gender $(P=0.126)$, and had to meet the following conditions: normoglycemia (fasting glucose $<5.6 \mathrm{mmol} / \mathrm{L}$ ) and no personal or first-degree history of diabetes. Diabetes diagnosis was based on clinical features as per World Health Organization criteria. None of the patients had ketoacidosis, and initial T2D treatment comprised diet and/or oral antidiabetic drugs; patients who required insulin had been treated with oral drugs for at least two years (Table 1). The patients had a mean age of 59.3 years (range $35-86$ years), BMI of $29.0 \mathrm{~kg} / \mathrm{m}^{2}$ (range $18.4-39.2 \mathrm{~kg} / \mathrm{m}^{2}$ ), and average T2D duration of 12.6 years (range 5 - 36 years), with 330 patients $(36.0 \%)$ reporting positive family history of diabetes. The control subjects had a mean age of 58.7 years (range 45 - 88 years), and mean BMI of $23.5 \mathrm{~kg} /$ $\mathrm{m}^{2}$ (range 18.2-27.0 kg/m²). None of the control subjects was taking regular medication, including slimming diet, 6 months prior to inclusion into the study.

Blood pressure (BP; right arm) was measured twice, using mercury sphygmomanometer with participants in the sitting position following a $5 \mathrm{~min}$ rest; the mean of two readings measured 1 minute apart was adopted. Hypertension was determined as BP readings of 145/90 $\mathrm{mmHg}$ or higher, and/or use of antihypertensive medications. Demographic details were obtained for all subjects, which included age, gender, BMI, age at onset and duration of diabetes, first-degree family history of diabetes, history of chronic diabetes complications, and treatment of diabetes. The historical information was verified from the clinic records where available. Written informed consent was obtained from all participants, and the study was carried out in accordance with the guidelines of the Helsinki Declaration of 1975, and was approved by the University of Monastir Ethics Committee. Venous blood samples were collected after an overnight fast for measuring plasma glucose, $\mathrm{HbA1c}$, and serum lipids.

\section{CAPN10 Genotyping}

Genomic DNA was isolated from the from the leukocyterich buffy coat layer of peripheral venous blood using a QIAamp DNA Blood Mini Kit (Qiagen, Valencia, CA). The study groups were genotyped for the CAPN10 UCSNP-43, -19, and -63 polymorphisms as previously described $[19,20]$. The insertion-deletion UCSNP-19 variant (rs3842570) was genotyped by PCR using the following primers, (forward) 5'-GTT TGG TTC TCT TCA GCG TGG AG-3' and (reverse) 5'-ATG AAC CCT GGC AG G GTC TAA G-3'. PCR fragments were separated on a $4 \%$ Nusieve agarose gel; the two 32 bp repeats $2 \mathrm{R}$ allele and the three 32 -bp repeats $3 \mathrm{R}$ allele visualized as $155 \mathrm{bp}$ and $187 \mathrm{bp}$, respectively. UCSNP-43 (rs3792267) was genotyped using the forward primer 5 '-CAC GCT TGC TGT GAA GTA ATG C-3', and the reverse primer, 5'CTC TGA TTC CCA TGG TCT GTA G-3', and subsequent digestion with NsiI (Promega, Madison, WI); the UCSNP-43 alleles seen as $144 \mathrm{bp}$ (G allele) $121+23 \mathrm{bp}$ fragments (A allele). UCSNP-63 (rs5030952) was genotyped using the forward primer 5 -AGC ACT CCC AGC TCC TGA TC-3' and the reverse primer 5'-AAG GGG GGC CAG GGC CTG ACG GGG GTG GCG-3', and digestion with HhaI (Promega); the UCSNP-63 alleles seen as $162 \mathrm{bp}$ (C allele) and $192 \mathrm{bp}$ fragment (T allele).

All genotyping was carried out in the same laboratory (University of Monastir), and was done in blinded fashion (case/control sample status). Inter-laboratory quality controls comprised independent genotyping of a number of case and control samples by personnel unaware of the phenotype of the samples. Genotyping call rate exceeded 
Table 1: Demographic and Clinical Characteristics of Study Subjects

\begin{tabular}{|c|c|c|c|}
\hline Characteristic & T2D Patients (917) & Controls (748) & $P$ \\
\hline Gender (M:F) & 422:495 & $373: 375$ & 0.126 \\
\hline Mean Age (years) & $59.3 \pm 10.9$ & $58.7 \pm 8.7$ & 0.160 \\
\hline Mean B.M.I. (kg/m2) & $27.7 \pm 4.3$ & $23.5 \pm 2.2$ & $<0.001$ \\
\hline Systolic BP (mmHg) & $140.7 \pm 27.0$ & $121.6 \pm 14.4$ & $<0.001$ \\
\hline Diastolic BP (mmHg) & $81.9 \pm 12.6$ & $77.9 \pm 10.5$ & $<0.001$ \\
\hline Hypertension ${ }^{2}$ & $420(45.8)$ & $86(18.0)$ & $<0.001$ \\
\hline Fasting glucose (mmol/L) & $12.8 \pm 5.3$ & $5.1 \pm 0.6$ & $<0.001$ \\
\hline HbA1c (\%) & $9.6 \pm 3.9$ & $4.5 \pm 1.4$ & $<0.001$ \\
\hline Age at disease onset (years) & $46.7 \pm 10.9$ & $\mathrm{~N} / \mathrm{A}$ & N/A \\
\hline T2D Duration (years) & $12.6 \pm 6.3$ & $\mathrm{~N} / \mathrm{A}$ & $\mathrm{N} / \mathrm{A}$ \\
\hline Total cholesterol (mmol/L) & $5.3 \pm 1.4$ & $4.7 \pm 1.2$ & $<0.001$ \\
\hline Triglycerides (mmol/L) & $1.9 \pm 1.3$ & $1.2 \pm 0.6$ & $<0.001$ \\
\hline $\mathrm{HDL}$ (mmol/L) & $1.1 \pm 0.3$ & $1.2 \pm 0.4$ & $<0.001$ \\
\hline LDL (mmol/L) & $3.8 \pm 1.4$ & $2.8 \pm 1.8$ & $<0.001$ \\
\hline Urea (mmol/L) & $7.9 \pm 4.8$ & $5.6 \pm 2.1$ & $<0.001$ \\
\hline
\end{tabular}

1. Student $t$-test for continuous variables, chi square for categorical variables.

2. Defined as BP reading $\geq 145 / 90 \mathrm{mmHg}$, and/or use of anti-hypertension medication.

99\%, with no significant differences between cases and control samples.

\section{Statistical Analysis}

Statistical analysis was performed on SPSS v.17.0 software (SPSS Inc., Chicago, IL). Data were expressed as mean \pm SD for continuous variables that were normally distributed, or as percentages of total for categorical variables. Pearson $\chi^{2}$ test were used to assess inter-group significance, and Student's $t$-test was used to determine differences in means. Allele frequencies were calculated by the gene-counting method, and differences in the allele and genotype frequencies were tested by $x^{2}$ test.

Haplotype estimation and determination of diplotype frequencies were done by the expectation maximization (EM) method using HPlus 2.5 software, which is an iterative method that alternates between performing an expectation (E) step (expectation of the log likelihood with respect to the current estimate of the distribution for the latent variables), and a maximization (M) step, which computes the parameters which maximize the expected log likelihood found in the E step. Univariate and multivariate regression analysis were determined using HPlus 2.5 and HAPStat; results being expressed as $p$ value, odds ratio (OR) and 95\% confidence intervals (CI). Statistical significance was set at $P<0.05$. The linkage disequilibrium among CAPN10 SNPs were calculated by an expectation-maximization algorithm and haplotype frequencies were estimated by LDA v.1.0 software [21].

\section{Results}

Study Subjects

The demographic and clinical characteristics of T2D patients and controls (Control/Case ratio $=0.82$ ) are shown in Table 1. Patients and control subjects were matched for gender, age, ethnic origin (all Arab subjects), and geographical origin (all originating from Central Tunisia); significant differences were noted between the two groups with regards to BMI $(P<0.001)$, blood pressure $(P<0.001)$, lipid profile $(P<0.001)$, urea $(P<0.001)$, and fasting glucose $(P<0.001)$ and HbA1c levels $(P<$ 0.001 ). T2D duration was 12.6 years (range: 5 - 36 years), with an average age at T2D onset of $46.7 \pm 10.9$ years.

\section{CAPN10 Allele and Genotype Frequencies}

The genotype frequencies of UCSNP-43 $\left(P=0.291 ; X^{2}=\right.$ 1.12), UCSNP-19 $\left(P=0.228 ; \chi^{2}=1.45\right)$, and UCSNP-63 $(P$ $\left.=0.506 ; \chi^{2}=0.44\right)$ were in Hardy-Weinberg Equilibrium. The distribution of UCSNP-43 genotypes (G/G, $P=$ 0.255 ; G/A, $P=0.332$, and A/A, $P=0.518$ ) or minor allele frequency (MAF) $(P=0.359)$, and UCSNP-63 genotypes $(\mathrm{C} / \mathrm{C}, P=0.702 ; \mathrm{C} / \mathrm{T}, P=0.895$, and T/T, $P=0.530)$ or MAF $(P=0.673)$ was similar between patients and controls (Table 2). The distribution of UCSNP-19 genotypes (3R/3R, $P=0.001,2 \mathrm{R} / 2 \mathrm{R}, P=0.020)$, and $\operatorname{MAF}(P=$ $0.007)$, were significantly different between patients and controls (Table 2). Homozygosity for the UCSNP-19 2R was associated with increased body weight among patients $(\mathrm{OR}=2.17 ; 95 \% \mathrm{CI}=1.33-3.51)$ (data not 
Table 2: UCSNP-43, UCSNP-19 and UCSNP-63 Allele and Genotype Distribution

\begin{tabular}{|c|c|c|c|c|}
\hline SNP & Allele/Genotype & Patients (917) & Controls (748) & $P 1$ \\
\hline \multirow[t]{4}{*}{ UCSNP-43 } & $\operatorname{MAF}^{2}(\mathbf{A})$ & 0.088 & 0.101 & 0.359 \\
\hline & $\mathrm{G} / \mathrm{G}$ & $759(0.828)$ & $602(0.805)$ & \\
\hline & $\mathrm{G} / \mathrm{A}$ & $155(0.178)$ & 141 (0.189) & 0.343 \\
\hline & $\mathrm{A} / \mathrm{A}$ & $3(0.003)$ & $5(0.007)$ & \\
\hline \multirow[t]{4}{*}{ UCSNP-19 } & MAF (2R) & 0.464 & 0.404 & 0.007 \\
\hline & $3 R / 3 R$ & $247(0.269)$ & $258(0.345)$ & \\
\hline & $3 R / 2 R$ & $489(0.533)$ & $376(0.503)$ & 0.001 \\
\hline & $2 \mathrm{R} / 2 \mathrm{R}$ & $181(0.197)$ & $114(0.152)$ & \\
\hline \multirow[t]{4}{*}{ UCSNP-63 } & $\operatorname{MAF}(\mathbf{T})$ & 0.162 & 0.170 & 0.673 \\
\hline & $\mathrm{C} / \mathrm{C}$ & $638(0.696)$ & $513(0.686)$ & \\
\hline & $\mathrm{C} / \mathrm{T}$ & $261(0.285)$ & $216(0.289)$ & 0.704 \\
\hline & $T / T$ & $18(0.020)$ & $19(0.025)$ & \\
\hline
\end{tabular}

1. Pearson chi square test

2. $\mathrm{MAF}=$ minor allele frequency.

shown). The association of UCSNP-19 genotypes with increased T2D risk was confirmed by regression analysis. Taking homozygous wild-type genotype as reference (OR $=1.00)$, regression analysis demonstrated progressive increases in T2D risk in $3 \mathrm{R} / 2 \mathrm{R}[P=0.008$; OR $(95 \% \mathrm{CI})=$ $1.35(1.08-1.68)]$ and $2 \mathrm{R} / 2 \mathrm{R}[P=0.002$; OR $(95 \% \mathrm{CI})=$ $1.61(1.20-2.18)]$ genotypes (Table 3$)$. The association of homozygous UCSNP-19 2R/2R $[P=0.044$; aOR $(95 \% \mathrm{CI})$ $=1.40(1.01-1.93)]$, but not $3 \mathrm{R} / 2 \mathrm{R}[P=0.923 ; \mathrm{aOR}(95 \%$ $\mathrm{CI})=1.02(0.66-1.58)]$ genotype with changes in BMI remained significant after controlling for age, gender, BMI, hypertension, and lipid profile (Table 3).

\section{Haplotype and Diplotype Distribution}

Linkage disequilibrium (LD) analysis for the CAPN10 variants, defined by the delta coefficient, showed a weak negative LD between these SNPs. LD among the three markers $\left(r^{2}\right)$ ranged from 0.001 to 0.083 in T2D subjects and from 0.002 to 0.076 in non-diabetic controls (Table 4). Six possible CAPN10 haplotypes were inferred, and neither haplotype 211 nor haplotype 212 was observed. Enrichment of only haplotype 111 was seen in patient $[P c$ $=0.034 ; \mathrm{OR}(95 \% \mathrm{CI})=1.22(1.06-1.41)]$; the distribution of the other haplotypes was comparable between unselected patients and control subjects (Table 5). Data from

Table 3: Regression Analysis on T2D Risk Associated with CAPN10 Polymorphisms 1

\begin{tabular}{|c|c|c|c|c|c|}
\hline \multirow[b]{2}{*}{ SNP } & \multirow[b]{2}{*}{ Genotype } & \multicolumn{2}{|c|}{ Univariate } & \multicolumn{2}{|c|}{ Multivariate } \\
\hline & & $P$ & OR $(95 \% \mathrm{Cl})$ & $P$ & $\mathrm{aOR}^{2}(95 \% \mathrm{Cl})$ \\
\hline \multirow[t]{3}{*}{ UCSNP-43 } & $\mathrm{G} / \mathrm{G}$ & 0.647 & 1.00 (Reference) $^{3}$ & 0.809 & 1.00 (Reference) $^{3}$ \\
\hline & $\mathrm{G} / \mathrm{A}$ & 0.573 & $1.52(0.35-6.53)$ & 0.827 & $1.20(0.24-6.12)$ \\
\hline & $\mathrm{A} / \mathrm{A}$ & 0.492 & $1.66(0.39-7.03)$ & 0.708 & $1.36(0.27-6.85)$ \\
\hline \multirow[t]{3}{*}{ UCSNP-19 } & $3 R / 3 R$ & 0.003 & 1.00 (Reference) ${ }^{3}$ & 0.084 & 1.00 (Reference) $^{3}$ \\
\hline & $3 R / 2 R$ & 0.008 & $1.35(1.08-1.68)$ & 0.923 & $1.02(0.66-1.58)$ \\
\hline & $2 \mathrm{R} / 2 \mathrm{R}$ & 0.002 & $1.61(1.20-2.18)$ & 0.044 & $1.40(1.01-1.93)$ \\
\hline \multirow[t]{3}{*}{ UCSNP-63 } & $\mathrm{C} / \mathrm{C}$ & 0.714 & 1.00 (Reference) $^{3}$ & 0.704 & 1.00 (Reference) $^{3}$ \\
\hline & $\mathrm{C} / \mathrm{T}$ & 0.463 & $1.29(0.66-2.52)$ & 0.722 & $1.19(0.45-3.17)$ \\
\hline & $T / T$ & 0.417 & $1.31(0.68-2.54)$ & 0.920 & $1.05(0.39-2.85)$ \\
\hline
\end{tabular}

1. Study subjects comprised 917 cases and 748 age-, gender-, and origin-matched controls subjects.

2. $\mathrm{aOR}=$ adjusted $\mathrm{OR}$; covariates included age, gender, BMI, hypertension, and lipid profile.

3. Reference group being minor allele non-carriers. 
Table 4: Linkage Disequilibrium Analysis Between CAPN10 SNPs 1

\begin{tabular}{|c|c|c|c|c|c|c|c|}
\hline \multirow[b]{2}{*}{ Locus 1} & \multirow[b]{2}{*}{ Locus 2} & \multicolumn{3}{|c|}{ T2D Patients $(n=917)$} & \multicolumn{3}{|c|}{ Controls $(n=748)$} \\
\hline & & $D^{\prime}$ & $r^{2}$ & $P$ & $D^{\prime}$ & $\mathbf{r}^{2}$ & $P$ \\
\hline UCSNP-43 & UCSNP-19 & 1.000 & 0.083 & $<0.001$ & 1.000 & 0.076 & $<0.001$ \\
\hline UCSNP-43 & UCSNP-63 & 0.360 & 0.002 & 0.190 & 0.284 & 0.002 & 0.314 \\
\hline UCSNP-19 & UCSNP-63 & 0.057 & 0.001 & 0.516 & 0.170 & 0.004 & 0.118 \\
\hline
\end{tabular}

1. Analyzed by LDA v.1.0 software.

Table 6 showed that the frequency of all CAPN10 diplotypes identified, including the "high-risk haplotype (112/ 121) reported for Mexican-Americans and Northern Europeans, were comparable between patients and controls, even before applying the Bonferroni correction.

\section{Discussion}

CAPN10 was the first T2D candidate gene identified through genome-wide screening and positional cloning $[3,8]$, and increasing evidence has implicated contribution of CAPN10 gene variants in the risk of T2D $[9,10,13]$. Specific CAPN10 variant (UCSNP-43) and atrisk haplotype combination $(112 / 121)$ defined by UCSNP-43, -19, and -63 polymorphisms, reportedly confers increased risk of T2D in some but not all populations $[4,9,11,13,15]$. Insofar as the Tunisian population (est. 9.6 million) is characterized by a high ethnic diversity, brought about by the admixture of the native Berbers (descendants of the Mesolithic Capsian populations) with principally the invading Arabs in the $7^{\text {th }}-8^{\text {th }}$ Century A.D. [22], we limited our study group to only Tunisians of Arab descent, so as to minimize the inherent problems associated with multi-ethnic genetic studies.

We previously investigated the contribution of some candidate gene variants identified through GWAS (TCF7L2, HHEX, GCK, ENPP1 and KCNJ11) to T2D in
Tunisian; only TCF7L2 (rs7903146) was significantly associated with T2D in Tunisians [18], thereby demonstrating ethnic contribution of the association of specific gene variants to T2D pathogenesis. In this case-control study, we examined the contribution of UCSNP-43, -19, and -63 CAPN10 variants on T2D risk in Tunisians of Arab origin, which were selected in view of previous reports linking them with T2D $[4,7,14]$, insulin resistance $[15]$, obesity $[7,9,15]$, or with altered regulation of CAPN10 gene expression in Tunisian and other populations. In the population studied, we could not confirm the previously described haplotype associated with T2D $(112 / 121)$ in Mexican-Americans and in northern-European populations [4,9-11]. UCSNP-19 was shown to affect the susceptibility to T2D, evidenced by enrichment of the $2 \mathrm{R}$ allele $(P=0.007$; OR $=1.15)$ and homozygous $2 \mathrm{R} / 2 \mathrm{R}$ genotype $(P=0.002$; OR $=1.61)$ in T2D patients.

In agreement with previous reports, UCSNP-19, but UCSNP-43 and UCSNP-63 was associated with heightened T2DM risk and increased BMI [6], without ruling out a role for UCSNP-43 and UCSNP-63 in the development of T2DM-related traits (insulin resistance, altered lipid metabolism), as was suggested [7,15]. Previous studies implicated UCSNP-19 with altered insulin sensitivity (HOMA-IR index) in Northern European [17] and Spanish [23], but not Scandinavian [15] or Finnish [7] subjects.

Table 5: CAPN10 Haplotype Analysis

\begin{tabular}{|c|c|c|c|c|c|}
\hline Haplotype ${ }^{1}$ & Patients & Controls & $P$ & Pc3 & OR $(95 \% \mathrm{CI})$ \\
\hline $111^{4}$ & $0.392(719)^{2}$ & $0.345(516)^{2}$ & 0.006 & 0.034 & $1.22(1.06-1.41)$ \\
\hline 112 & $0.072(132)$ & $0.059(88)$ & 0.147 & 0.615 & $1.24(0.94-1.64)$ \\
\hline 121 & $0.368(675)$ & $0.399(597)$ & 0.072 & 0.361 & $0.88(0.76-1.01)$ \\
\hline 122 & $0.080(147)$ & $0.096(144)$ & 0.115 & 0.520 & $0.82(0.64-1.04)$ \\
\hline 221 & $0.078(143)$ & $0.086(129)$ & 0.422 & 0.963 & $0.90(0.70-1.15)$ \\
\hline 222 & $0.010(18)$ & $0.015(22)$ & 0.259 & 0.834 & $0.66(0.36-1.24)$ \\
\hline
\end{tabular}

1. Haplotype frequency determined by the maximum likelihood method.

2. Haplotype frequency (number of haplotypes).

3. $P C=$ corrected $P$, calculated as per the Bonferroni method $\left.\left[P C=1-(1-P)^{n}\right)\right]$, where $\mathrm{n}=$ number of comparisons.

4. CAPN10 haplotypes were coded as per the allele at each locus (wild-type $=1$, mutant $=2$ ); the first refers to UCSNP-43, the second to UCSNP-

19 , and the third to UCSNP-63. 
Table 6: CAPN10 Haplotype Combinations

\begin{tabular}{|c|c|c|c|c|c|}
\hline Diplotype $^{1}$ & Patients & Controls & $P$ & $P c^{2}$ & $\mathrm{OR}^{3}(95 \% \mathrm{Cl})$ \\
\hline $111 / 111$ & $132(0.144)^{4}$ & $88(0.118)$ & 0.133 & 0.864 & $1.26(0.94-1.70)$ \\
\hline $111 / 112$ & $45(0.049)$ & $23(0.031)$ & 0.079 & 0.684 & $1.63(0.97-2.67)$ \\
\hline $111 / 121$ & $260(0.284)$ & $193(0.258)$ & 0.268 & 0.987 & $1.14(0.91-1.41)$ \\
\hline $111 / 221$ & $76(0.083)$ & $57(0.076)$ & 0.683 & 1.000 & $1.10(0.76-1.56)$ \\
\hline $112 / 112$ & $4(0.004)$ & $3(0.004)$ & 0.947 & 1.000 & $0.81(0.22-3.02)$ \\
\hline $112 / 121$ & $115(0.125)$ & $87(0.116)$ & 0.624 & 1.000 & $1.09(0.81-1.46)$ \\
\hline $112 / 221$ & $28(0.031)$ & $32(0.043)$ & 0.230 & 0.974 & $0.70(0.42-1.18)$ \\
\hline $121 / 121$ & $132(0.144)$ & $131(0.175)$ & 0.095 & 0.753 & $0.79(0.61-1.03)$ \\
\hline $121 / 221$ & $35(0.038)$ & $39(0.052)$ & 0.194 & 0.951 & $0.72(0.45-1.15)$ \\
\hline $221 / 221$ & $3(0.003)$ & $5(0.007)$ & 0.519 & 1.000 & $0.49(0.13-1.98)$ \\
\hline $112 / 122$ & $10(0.011)$ & $7(0.009)$ & 0.946 & 1.000 & $1.17(0.45-2.93)$ \\
\hline $121 / 122$ & $58(0.063)$ & $62(0.083)$ & 0.148 & 0.894 & $0.75(0.52-1.08)$ \\
\hline $122 / 122$ & $3(0.003)$ & $8(0.011)$ & 0.120 & 0.833 & $0.30(0.10-1.16)$ \\
\hline $122 / 221$ & $16(0.017)$ & $13(0.017)$ & 0.859 & 1.000 & $1.00(0.48-2.06)$ \\
\hline
\end{tabular}

1. CAPN10 haplotypes were coded as per the allele ( wild-type $=1$, mutant $=2$ ) at each locus; the first refers to UCSNP-43, the second to UCSNP19 , and the third to UCSNP-63.

2. $P C=$ corrected $P$, calculated as per the Bonferroni method $\left.\left[P C=1-(1-P)^{\mathrm{n}}\right)\right]$, where $\mathrm{n}=$ number of comparisons.

3. Calculated according to Woolf's method, for specific patient $v s$. control diplotype carriers.

4. Number (frequency).

Our findings were in agreement with a recent small study in Southern Tunisia (Djerba Island) involving 162 T2D patients and 110 control subjects of mixed Arab and nonArab (Berber) ancestry, in which UCSNP-19 was associated with T2D only in the Arab sub-group [24], and in apparent disagreement with another study in Central Tunisia (Sfax), in which UCSNP-43, but not UCSNP-19, was over-represented in T2D patients [25]. While explanations for the discrepancies remain to be seen, they most likely reside in inadequate statistical power in the study of Kifagi (226 patients and 206 controls), and in differences in subjects' selection (gender distribution, duration of diabetes, BMI status), which in turn may have overestimated the association of UCSNP-43 with T2D.

In the Tunisian population studied herein, the most frequent haplotypes were 111 in patients $(\mathrm{OR}=1.22)$ and 121 among controls $(\mathrm{OR}=0.88)$, while haplotype 112 was detected at low frequencies among controls (0.059) and patients (0.072). Haplotype 112 is common among Africans and Asians, but is infrequent in Caucasians, while haplotype 121 is infrequent in Africans, but common among Europeans $[8,26]$. This relatedness of North African Tunisians to Europeans in the distribution of the CAPN10 haplotypes, more so than Africans, may be explained by the admixture of indigenous African inhabitants (Berbers) with Phoenicians (ancestors of presentday Lebanese), followed by successive migration of Muslims from Arabian Peninsula, Turks (Ottoman rule), and recently Europeans. The positive association of haplotype 111 with T2D among Tunisians was reminiscent of previous results linking haplotype 111 with increased T2D risk in Koreans [27], and with altered insulin sensitivity in Spanish subjects [23]. The reason for discrepancies in the association of specific CAPN10 haplotypes, especially 111 haplotype rather than the anticipated 121 haplotype with T2D remains speculative at this stage. The heterogeneity of CAPN10 in the magnitude of LD between CAPN10 variants is likely attributed to ethnic differences, coupled with sample size differences, and to the failure to control for possible confounding variables by some of the studies. Collectively, this may have modulated potential effects of CAPN10 gene variants on T2D.

Since the first report of Horikawa linking specific CAPN10 at-risk haplotype combination (112/121) (defined by UCSNP-43, -19 and -63), with higher risk of T2D in Mexican-Americans and Europeans [10], a number of studies performed on diverse populations yielded often inconsistent association of CAPN10 diplotypes with T2D risk $[9,10]$. These haplotype combinations included 111/121 in Koreans [27], 111/221 in Northern Europeans [17], 112/221 in Chinese [12], and 121/121 in pan-Eurpoean populations [9]. We did not identify specific T2D at-risk CAPN10 haplotype combination, including the 112/121 diplotype, which was present at comparable frequencies among healthy controls and T2D patients. 
Our findings were in agreement with those reported for the Scandinavians [15], Koreans [27], and Mexicans [11] and in meta-analysis conducted in both population-based and family-based association studies [26] and in prospective cohort study of multi-ethnic American postmenopausal women [28], in which 112/121 diplotype did not influence the risk of T2D. It was of interest to note the association of 121/221 diplotype with increased risk of T2D among Tunisians (South East Tunisia) [25]. While the frequency of this diplotype was comparable between our healthy control group (0.052) and their control cohort (0.05), marked difference its distribution among T2D patients was seen between our (0.038) and their (0.108) T2D patient groups. These discrepancies may be explained by differences in sample size (226 patients and 206 controls in Kifagi study vs. 917 patients and 748 controls in our study), and thus statistical power, differences in patient characteristics (BMI, hypertension status, and T2D duration), and data presentation. Future large-scale association and functional studies are needed to confirm or argue against the association of a particular CAPN10 haplotype combination with T2D risk, after controlling for the ethnic/geographical factor.

\section{Conclusion}

In conclusion, we were not able to replicate the association between specific CAPN10 alleles identified in earlier studies and T2D in Tunisians of Arab ancestry. The difference in the association between CAPN10 variants with increased risk of T2D between populations (Mexican Americans, northern-Europeans, Pima Indians) may be attributed to the presence of multiple susceptibility alleles at CAPN10 locus, to different linkage disequilibrium patterns of between these variants (and hence haplotypes and haplotype combinations), racial/ethnic differences in the distribution of CAPN10 variants, multiple hypothesis testing, and to inadequate statistical power in a number of these studies, which has likely overestimated this genetic association. However, our study has some limitations. It was limited to three SNPs which were selected based on previous reports, leaving the possibility of the contribution of other CAPN10 SNPs to T2DM pathogenesis among Tunisians to be addressed, together with the speculation as to if the three SNPs analyzed were sufficient to capture the genetic variability in Tunisian Arabs. In addition, we did not assign a functional aspect to the CAPN10 variants and haplotypes included, and it was limited to a specific ethnic group (North African Tunisian Arabs). These, coupled with the potential linkage of CAPN10 polymorphisms investigated with other CAPN10 or nearby gene polymorphisms, necessitates large population-based follow-up studies for better understanding of the contribution that CAPN10 to T2D risk.

\section{Abbreviations}

CAPN10: Calpain 10; BMI: Body Mass Index; Cl: Confidence Interval; MAF: Minor Allele Frequency; OR: Odds Ratio; PCR: Polymerase Chain Reaction; SNP: Single Nucleotide Polymorphism; T2D: Type 2 Diabetes.

\section{Competing interests}

The authors declare that they have no competing interests.

\section{Authors' contributions}

IE participated in the design of the study, carried out the SNP genotyping and the analyses of the genotype data, and contributed to the statistical analyses and the drafting of the manuscript. AT and SM participated in the SNP genotyping and some of the genetic analyses. MC and MK coordinated the patients' recruitment. GMAK and TM contributed to the manuscript editing. WYA and NM contributed to the design and coordination of the study, to the statistical analyses and drafted the manuscript. All authors read and approved the final manuscript.

\section{Acknowledgements}

The authors gratefully acknowledge the members of the Endocrinology (Pr. Larbi CHAIEB) and Internal Medicine (Dr. Hela MARMOUCHE) departments at Sousse and Monastir University Hospitals, who contributed to the patient's recruitment. We are also grateful to all subjects who participated to this study.

\section{Author Details}

${ }^{1}$ Research Unit of Biology and Genetics of Hematological and Auto-immune diseases, Faculty of Pharmacy of Monastir, University of Monastir, Tunisia, 2Higher Institute of Biotechnology of Monastir, University of Monastir, Tunisia, 3Endocrinology and Diabetic Service, CHU Farhat Hached of Sousse, Tunisia, ${ }^{4}$ Nephrology and Internal Medicine Service, CHU Fatouma Bourguiba, Monastir, Tunisia and 5 Dept. Medical Biochemistry, Arabian Gulf University, Manama, Bahrain

Received: 4 December 2009 Accepted: 15 May 2010

Published: 15 May 2010

\section{References}

1. Ghosh S, Watanabe RM, Hauser ER, Valle T, Magnuson VL, Erdos MR, Langefeld CD, Balow J Jr, Ally DS, Kohtamaki K, et al:: Type 2 diabetes: evidence for linkage on chromosome 20 in 716 Finnish affected sib pairs. Proc Natl Acad Sci USA 1999, 96(5):2198-2203

2. Wiltshire S, Hattersley AT, Hitman GA, Walker M, Levy JC, Sampson M, O'Rahilly S, Frayling TM, Bell Jl, Lathrop GM, et al:: A genomewide scan for loci predisposing to type 2 diabetes in a U.K. population (the Diabetes UK Warren 2 Repository): analysis of 573 pedigrees provides independent replication of a susceptibility locus on chromosome 1q. Am J Hum Genet 2001, 69(3):553-569.

3. Cox NJ, Hayes MG, Roe CA, Tsuchiya T, Bell Gl: Linkage of calpain 10 to type 2 diabetes: the biological rationale. Diabetes 2004, 53(Suppl 1):S19-25.

4. Weedon MN, Schwarz PE, Horikawa Y, Iwasaki N, Illig T, Holle R, Rathmann W, Selisko T, Schulze J, Owen KR, et al.: Meta-analysis and a large association study confirm a role for calpain-10 variation in type 2 diabetes susceptibility. Am J Hum Genet 2003, 73(5):1208-1212.

5. Dear TN, Boehm T: Identification and characterization of two novel calpain large subunit genes. Gene 2001, 274(1-2):245-252.

6. Carlsson E, Poulsen P, Storgaard H, Almgren P, Ling C, Jensen CB, Madsbad S, Groop L, Vaag A, Ridderstrale M: Genetic and nongenetic regulation of CAPN10 mRNA expression in skeletal muscle. Diabetes 2005, 54(10):3015-3020.

7. Pihlajamaki J, Salmenniemi U, Vanttinen M, Ruotsalainen E, Kuusisto J, Vauhkonen I, Kainulainen S, Ng MC, Cox NJ, Bell Gl, et al:: Common polymorphisms of calpain-10 are associated with abdominal obesity in subjects at high risk of type 2 diabetes. Diabetologia 2006, 49(7):1560-1566.

8. Fullerton SM, Bartoszewicz A, Ybazeta G, Horikawa Y, Bell Gl, Kidd KK, Cox NJ, Hudson RR, Di Rienzo A: Geographic and haplotype structure of candidate type 2 diabetes susceptibility variants at the calpain-10 locus. Am J Hum Genet 2002, 70(5):1096-1106.

9. Tsuchiya T, Schwarz PE, Bosque-Plata LD, Geoffrey Hayes M, Dina C, Froguel P, Wayne Towers G, Fischer S, Temelkova-Kurktschiev T, Rietzsch 
$H$, et al:: Association of the calpain-10 gene with type 2 diabetes in Europeans: results of pooled and meta-analyses. Mol Genet Metab 2006, 89(1-2):174-184.

10. Horikawa Y, Oda N, Cox NJ, Li X, Orho-Melander M, Hara M, Hinokio Y, Lindner TH, Mashima H, Schwarz PE, et al:: Genetic variation in the gene encoding calpain-10 is associated with type 2 diabetes mellitus. Nat Genet 2000, 26(2):163-175.

11. del Bosque-Plata L, Aguilar-Salinas CA, Tusie-Luna MT, Ramirez-Jimenez S, Rodriguez-Torres M, Auron-Gomez M, Ramirez E, Velasco-Perez ML, Ramirez-Silva A, Gomez-Perez F, et al:: Association of the calpain-10 gene with type 2 diabetes mellitus in a Mexican population. Mol Genet Metab 2004, 81(2):122-126.

12. Chen SF, Lu XF, Yan WL, Huang JF, Gu DF: Variations in the calpain-10 gene are associated with the risk of type 2 diabetes and hypertension in northern Han Chinese population. Chin Med J (Engl) 2007 120(24):2218-2223.

13. Iwasaki N, Horikawa Y, Tsuchiya T, Kitamura Y, Nakamura T, Tanizawa Y, Oka Y, Hara K, Kadowaki T, Awata T, et al:: Genetic variants in the calpain10 gene and the development of type 2 diabetes in the Japanese population. J Hum Genet 2005, 50(2):92-98.

14. Garant MJ, Kao WH, Brancati F, Coresh J, Rami TM, Hanis CL, Boerwinkle E, Shuldiner AR: SNP43 of CAPN10 and the risk of type 2 Diabetes in African-Americans: the Atherosclerosis Risk in Communities Study. Diabetes 2002, 51(1):231-237.

15. Rasmussen SK, Urhammer SA, Berglund L, Jensen JN, Hansen L, Echwald SM, Borch-Johnsen K, Horikawa Y, Mashima H, Lithell H, et al:: Variants within the calpain-10 gene on chromosome 2q37 (NIDDM1) and relationships to type 2 diabetes, insulin resistance, and impaired acute insulin secretion among Scandinavian Caucasians. Diabetes 2002, 51(12):3561-3567.

16. Tsai HJ, Sun G, Weeks DE, Kaushal R, Wolujewicz M, McGarvey ST, Tufa J, Viali S, Deka R: Type 2 diabetes and three calpain-10 gene polymorphisms in Samoans: no evidence of association. Am J Hum Genet 2001, 69(6):1236-1244.

17. Elbein SC, Chu W, Ren Q, Hemphill C, Schay J, Cox NJ, Hanis CL, Hasstedt $\mathrm{SJ}$ : Role of calpain-10 gene variants in familial type 2 diabetes in Caucasians. J Clin Endocrinol Metab 2002, 87(2):650-654.

18. Ezzidi I, Mtiraoui N, Cauchi S, Vaillant E, Dechaume A, Chaieb M, Kacem M, Almawi WY, Froguel P, Mahjoub T, Vaxillaire M: Contribution of type 2 diabetes associated loci in the Arabic population from Tunisia: a casecontrol study. BMC Med Genet 2009, 10:33.

19. Evans JC, Frayling TM, Cassell PG, Saker PJ, Hitman GA, Walker M, Levy JC, O'Rahilly S, Rao PV, Bennett AJ, et al:: Studies of association between the gene for calpain-10 and type 2 diabetes mellitus in the United Kingdom. Am J Hum Genet 2001, 69(3):544-552.

20. Horikawa Y, Oda N, Yu L, Imamura S, Fujiwara K, Makino M, Seino Y, Itoh M, Takeda J: Genetic variations in calpain-10 gene are not a major factor in the occurrence of type 2 diabetes in Japanese. J Clin Endocrinol Metab 2003, 88(1):244-247.

21. Abecasis GR, Cookson WO, Cardon LR: Pedigree tests of transmission disequilibrium. Eur J Hum Genet 2000, 8(7):545-551.

22. Hajjej A, Kâabi H, Sellami MH, Dridi A, Jeridi A, El borgi W, Cherif G, Elgaâied A, Almawi WY, Boukef K, Hmida S: The contribution of HLA class I and II alleles and haplotypes to the investigation of the evolutionary history of Tunisians. Tissue Antigens 2006, 68(2):153-162.

23. Saez ME, Gonzalez-Sanchez JL, Ramirez-Lorca R, Martinez-Larrad MT, Zabena C, Gonzalez A, Moron FJ, Ruiz A, Serrano-Rios M: The CAPN10 gene is associated with insulin resistance phenotypes in the Spanish population. PLoS One 2008, 3(8):e2953.

24. Ouederni TB, Sanchez-Corona J, Skhiri HA, Maiz HB, Abid HK, BenammarElgaaied A: [Study of association of the SNP19 polymorphism of calpain 10 gene with type 2 diabetes in ethnic sub-groups of the Tunisian population: gene-environment interaction]. Ann Biol Clin (Paris) 2009, 67(2):171-176.

25. Kifagi C, Makni K, Mnif F, Boudawara M, Hamza N, Rekik N, Abid M, Rebai A, Granier C, Jarraya F, et al:: Association of calpain-10 polymorphisms with type 2 diabetes in the Tunisian population. Diabetes Metab 2008, 34(3):273-278.

26. Song Y, Niu T, Manson JE, Kwiatkowski DJ, Liu S: Are variants in the CAPN10 gene related to risk of type 2 diabetes? A quantitative assessment of population and family-based association studies. Am J Hum Genet 2004, 74(2):208-222.
27. Kang ES, Kim HJ, Nam M, Nam CM, Ahn CW, Cha BS, Lee HC: A novel 111/ 121 diplotype in the Calpain-10 gene is associated with type 2 diabetes. J Hum Genet 2006, 51(7):629-633.

28. Song Y, You N, Hsu YH, Sul J, Wang L, Tinker L, Eaton CB, Liu S: Common genetic variation in calpain-10 gene (CAPN10) and diabetes risk in a multi-ethnic cohort of American postmenopausal women. Hum Mol Genet 2007, 16(23):2960-2971.

\section{Pre-publication history}

The pre-publication history for this paper can be accessed here: http://www.biomedcentral.com/1471-2350/11/75/prepub

doi: 10.1186/1471-2350-11-75

Cite this article as: Ezzidi et al., Common polymorphisms of calpain-10 and the risk of Type 2 Diabetes in a Tunisian Arab population: a case-control study BMC Medical Genetics 2010, 11:75

\section{Submit your next manuscript to BioMed Central and take full advantage of:}

- Convenient online submission

- Thorough peer review

- No space constraints or color figure charges

- Immediate publication on acceptance

- Inclusion in PubMed, CAS, Scopus and Google Scholar

- Research which is freely available for redistribution

Submit your manuscript at www.biomedcentral.com/submit
C) Biomed Central 